\title{
EM BUSCA DE NOVAS SOLIDARIEDADES: OS EMPREENDIMENTOS DA ECONOMIA SOCIAL EM QUESTÃO
}

\author{
Ricardo Augusto Alves de Carvalho \\ Sanyo Drummond Pires
}

\begin{abstract}
Resumo. Trata-se, neste artigo, de colocar em discussão as noções de autogestão e de autonomia, tanto do ponto de vista teórico como metodológico, no contexto dos empreendimentos de autogestão. Procuramos, portanto, propor neste trabalho, a necessidade de se identificar as relações entre os seguintes níveis de análise: jurídico-econômico, político-administrativo e psicossocial, na tensão que se faz sentir entre os processos de autonomia e de heteronomia. Poderíamos pensar o sujeito na sua relação com "o outro" em um novo terreno de "co-laboração"? Nestas novas configurações sócio-autogestionárias, o laço social não poderia estar se realizando sob a forma de "dádiva"?
\end{abstract}

Palavras-chaves: autogestão, autonomia, dádiva, psicossocial, economia solidária

... O que permanece, em compensação, é a possibilidade de cada sociedade e de cada pessoa entrever a dificuldade do caminho e de, às

Ricardo Augusto Alves de Carvalho é coordenador Regional da UNITRABALHO + Rede Interuniversitária de Estudos e Pesquisas sobre o Trabalho, coordenador regional (MG) da pesquisa "Significados e Tendências da Economia Solidária no Brasil"; professor adjunto da FAFICH/UFMG, doutor em Sociologia Paris VII.

Sanyo Drummond Pires é psicólogo, filósofo e pesquisador da Rede Interuniversitária de Estudos e Pesquisas sobre o Trabalho no projeto "Significados e Tendências da Economia Solidária no Brasil" (UNITRABALHO).

O presente artigo é, em grande parte, produto das discussões realizadas pelo grupo de pesquisa sobre autogestão e processos psicossociais, do Núcleo de Estudo Sobre o Trabalho Humano (NESTH) da UFMG, que conta com a participação de Ana Rita de Castro Trajano (Mestrado em Psicologia Social da UFMG), Carla Fonseca Lopes; Lívia S. Toma; Luciana O. Morais e Selene C. Saldanha (bolsistas de Iniciação Científica e de Extensão). 
vezes, arriscar-se por ele. Tanto quanto é impossível chegar à verdade, é impossível atingir a autonomia. Nem por isso a busca da verdade e da autonomia devem terminar. Saber que perseguimos um fim impossível nos chama, simplesmente, para um pouco de modéstia, de humor e de ironia, em relação a nós mesmos e a nossas possibilidades de influência. Talvez seja ao atingir a consciência de nossas impossibilidades que cheguemos, mais freqüentemente, a nos conduzir de maneira autônoma e a não nos deixar prender nas ilusões que o social difunde e das quais o ser humano é particularmente ávido... Se, às vezes, os heróis ficam cansados, em outros momentos, podem se reerguer e nos surpreender. Aceitemos o augúrio e trabalhemos cotidianamente para fazer da 'vida imediata' (Eluard) mais um lugar de surpresas do que um lugar de repetição morna. (Enriquez, 1994, p. 40)

A solidariedade enquanto forma de conhecimento é a condição necessária da solidariedade enquanto prática política. Mas a solidariedade só será um senso comum político na medida em que for um senso comum tout court. (Santos, 2000, p. 108)

Pois aquilo que marcava e que continua a marcar o dom entre próximos não é a ausência de obrigações, é a ausência de 'cálculo'. (Godelier, 2000, p. 13)

\section{Introdução}

No final do século XIX e princípio do século XX, quando da implantação do sistema de produção fabril, como sabemos, foram criadas inovações técnicas e organizacionais articuladas, onde o principal objetivo era a produção e o consumo em larga escala. Estas inovações têm sobretudo no taylorismo/fordismo sua base fundamental ao nível da gestão do trabalho, introduzindo, de forma definitiva, a separação entre concepção e execução. Esta última baseia-se no trabalho fragmentado, simplificado através de uma rígida disciplina que estabelece que o operário execute a mesma tarefa. Esse tipo de atividade exige pouca qualificação e as que restam são incorporadas à máquina. Já o trabalho de concepção exigiria alta qualificação, pois é realizado separadamente, fora do chão de fábrica, e resume se à configuração do produto, à administração e à programação da produção, da manutenção e reparação. Verifica-se, portanto, que se trata de um sistema altamente rígido, padronizado, controlador, que estabelece um hierarquia bem definida 
devido à intensa divisão técnica do trabalho. Neste sentido estamos no reino da heteronomia no trabalho, reproduzindo, por assim dizer a heteronomia societal.

No entanto, a grande diferença que constatamos neste atual fase - caracterizada como neo-liberal - do capitalismo, é um movimento de mobilidade das empresas de todo porte, jamais observada anteriormente, no que tange à variedade de alianças, fusões, aquisições e incorporações entre essas empresas, assim como processos e esquemas de subcontratação e contratação temporária colorindo o mundo da "inserção" no trabalho de uma precariedade sem par, redesenhando novas direções em nível das relações de trabalho em escala mundial, cujos contornos mais nítidos ainda estão por se definir.Acrescentaríamos que além dessas mudanças apontadas nas diferentes áreas da vida social, constatamos mudanças profundas na esfera psicossocial do sujeito trabalhador. Isto é, vive-se atualmente um momento onde a reestruturação (sócio) ${ }^{1}$-produtiva que segue as redefinições impostas pela globalização, reconfigura e tenta determinar de forma hegemônica, as esferas do mundo do trabalho e do mundo da vida.

Constatamos através da última reestruturação produtiva do capital, uma intensa flexibilização sistêmica marcada pelo rompimento dos padrões, pela negação da compulsão repetitiva sustentada pelo fordismo, pela versatilidade e criatividade exigidas do trabalhador e por uma certa descentralização do poder. Pode-se dizer que este último é mais difundido e que cria ou propõe maior "autonomia" ao empregado, desde que ele siga a filosofia e a política da organização. Portanto sua "autonomia", se seguirmos uma justa definição dessa palavra e do seu significado é relativa, pois não é real e, sim, controlada.

Assiste-se assim a uma transição de um modelo estruturalmente burocrático e autoritário - principalmente no chamado fordismo incompleto adotado nos países periféricos - que sustentava um trabalhador de mínima qualificação e que restringia sua autonomia devido a uma intensa hierarquização - para um modelo altamente flexível, "sem fronteiras", que se ajusta facilmente às inovações tecnológicas e organizacionais, às imposições e constantes mudanças do mercado, tendo como principal arma sujeitos com alto padrão de 
qualificação e que se sustentam no implacável mundo do trabalho através de suas experiências, informações, da capacidade para trabalhar em equipe com o objetivo de se assegurar a chamada coesão social na empresa.

No entanto este modelo longe de propiciar, como se apregoava, o desenvolvimento e o emprego, produziu, como se sabe, o desemprego e inúmeras empresas falidas.

Neste contexto de plena crise, o movimento de autogestão (res) nasce no Brasil, na década de 90, a partir de mobilizações dos trabalhadores pela defesa do trabalho, sendo seus primeiros militantes oriundos do movimento sindical (Sindicato dos Químicos de São Paulo, Sindicato dos Sapateiros de Franca), e tendo como experiência pioneira, já em 1992, a fábrica de calçados Markely, em Franca, no interior de São Paulo. Nessa época foi negociado com os empresários a compra do maquinário, buscando financiamento junto a órgãos governamentais, ${ }^{2}$ com apoio técnico do DIEESE.

O movimento de autogestão vem se constituindo como um movimento cada vez mais amplo e em escala mundial, inserindo-se, dessa forma, numa conjuntura de buscas de solução para os problemas gerados pela globalização excludente no que se refere ao mundo do trabalho.

No Brasil, este movimento se amplia e se fortalece com a participação de trabalhadores, visando à construção de uma nova realidade do trabalho, enfrentando o momento desfavorável de desemprego, destruição de postos de trabalho, fechamento de fábricas. Mais recentemente, vemos a criação de Redes de Autogestão e Socioeconomia Solidária, em níveis locais, regionais e nacional, a Rede Brasileira de Socioeconomia Solidária, criada em junho de 2000, durante o Encontro Brasileiro de Cultura e Socioeconomia Solidárias, realizado entre os dias 11 e 18 de junho de 2000, em Mendes, Estado do Rio de Janeiro. Em seu primeiro número (jan. 2001), o jornal dessa Rede - $O$ Girassol-, sintetiza princípios e concepções do movimento, referindose a um outro evento, o Encontro Latino-americano de Cultura e Socioeconomia Solidárias, realizado em Porto Alegre, Estado do Rio Grande do Sul, em 1998, como o passo inicial para a posterior criação 
da Rede Brasileira. Vemos nesta perspectiva que, segundo Singer(2001), no Brasil, ${ }^{3}$ este movimento atinge dimensões mais amplas, com apoio de igrejas, sindicatos, governos municipais e estaduais.

Uma Rede Global de Socioeconomia Solidária é projetada tendo como base as idéias expressas nos documentos elaborados durante os encontros supracitados, sendo o seu lançamento preparado para ocorrer durante o evento internacional, que se realizou entre os dias 25 e 30 de janeiro de 2001, em Porto Alegre, o Fórum Social Mundial. ${ }^{4}$ Em 29 de janeiro de 2001, concretiza-se o lançamento desta Rede Global, tendo por objetivo maior, expresso em documento elaborado nessa ocasião:

... avançar na integração e no intercâmbio de informações, produtos, serviços e valores, contribuindo para a consolidação de todas as organizações de economia solidária que compartilhem destes princípios básicos, e para a elaboração coletiva de um novo paradigma socioeconômico, político e cultural fundado na solidariedade.

Neste cenário podemos observar já a clara delimitação de princípios e critérios que nortearão os chamados EAs (Empreendimentos de Autogestão), assim como as formas de participação nesta Rede Global:

a) que nos empreendimentos que venham a fazer parte desta rede não exista qualquer tipo de exploração do trabalho;

b) que se busque preservar o equilíbrio ecológico dos ecossistemas (respeitando-se todavia a transição de empreendimentos que ainda não sejam ecologicamente sustentáveis);

c) que os empreendimentos disponham-se a compartilhar significativas parcelas de seu excedente para a expansão da própria rede, viabilizando a organização de novos empreendimentos econômicos, remontando de maneira solidária e ecológica as cadeias produtivas, gerando postos de trabalho e distribuição de renda, como objetivo de garantir as condições econômicas para o exercício das liberdades públicas e privadas eticamente exercidas.

Aqui não estaríamos, como afirma Godelier (2000, p.314), na perspectiva do “dom' dentro de (...) “uma ética e de uma lógica que não são as de mercado e do lucro (...), mas uma lógica que antes de tudo 
resiste à lógica mercantil? Buscando indicadores, temos na análise de Mance (1999), o que ele nomeia como uma revolução das redes, em processo de criação pelos movimentos sociais e sindicais, como "uma alternativa pós-capitalista à globalização atual”.

Estudos, pesquisas e projetos de ação se estruturam nesse movimento, envolvendo entidades sindicais como a Central Única dos Trabalhadores (CUT), que criou a Agência de Desenvolvimento Solidário, em dezembro de 1999, buscando parcerias nacionais e internacionais, dentre as quais se encontra a UNITRABALHO - Rede Interuniversitária de Estudos e Pesquisas sobre o Trabalho - hoje composta por 80 universidades no Brasil. Cabe aqui ressaltar o Projeto Integrar Cooperativas, como fruto de ações conjuntas entre a Unitrabalho e CUT, contribuindo para uma prática sindical que incorpore os trabalhadores sem-trabalho, favorecendo sua organização e a criação de alternativas de trabalho.

Estes projetos já apontam uma realidade em construção pelos trabalhadores, acenando para a necessidade de uma maior articulação entre esses empreendimentos, em forma de rede de trocas de produtos, serviços e saberes. Uma das dificuldades levantadas é como "conciliar o desenvolvimento humano com a lógica do mercado", quando a atividade econômica não é a finalidade do empreendimento mas, sim, o meio de se atingir o desenvolvimento humano. Nesta perspectiva, a chamada economia solidária nos empreendimentos "exitosos" não estaria se constituindo uma espécie de refúgio e morada (ethos) para as chamadas novas solidariedades urbanas, onde o "dom”, a partilha não portaria um devir social, uma teleologia carregada de utopia ativa?

Retomamos aqui a reflexão feita por Godelier (2000) no princípio deste artigo e, indagamos se não é também a ausência de cálculo que a marcaria a relação de colaboração nos empreendimentos autogestivos e se nestas novas formas de 'integração', não veríamos aí o “integrare”, significando também o restituir da tríade da dádiva, em respeito aos empreendimentos autogestivos coletivamente, antes propriedade de um outrem? Sem querer propor d'emblé uma resposta inequívoca, iremos discutir um pouco mais a relação entre autogestão, autonomia e heteronomia. 


\section{Autogestão: entre a autonomia e a heteronomia - novas solidariedades}

Estamos a tratar de uma mudança, de uma reestruturação, de uma transição. Nesta direção, deve-se também levar em conta a possibilidade de um choque cultural: nos empreendimentos de autogestão, o sujeitotrabalhador deve se desvencilhar e/ou romper as regras há muito estabelecidas por um modelo de caráter nitidamente heterogestivo e muitas vezes autoritário. Essa capacidade de mudança implica uma "capacidade" de mobilizar sua subjetividade (antes praticamente desconsiderada no paradigma taylorista/fordista) para um modelo autogestivo, onde terá que lidar com a crítica, com a argumentação, com a escuta, com a negociação e com todos os processos de interação grupal. O que antes era camuflado (através de uma estrutura discursiva que tinha como suporte ideológico a democracia industrial - oriunda da escola sociotécnica) vem à tona e a capacidade para lidar com o que estava implícito passa a fazer parte de um novo perfil profissional exigido no mercado.

Vamos examinar de que forma este novo paradigma produtivo se estrutura em empresas de autogestão que têm, por princípio, a autonomia como valor de base. Os empreendimentos de autogestão podem ser compreendidos como sistemas organizacionais complexos, onde encontramos presente na práxis laboral processos efetivos de cooperação entre seus membros. Podemos dizer que uma das características essenciais desse modelo de gestão é a descentralização das decisões e a autonomia decisória conferida aos membros da organização, pois se responsabilizam pela produção e pela gestão da empresa de forma coletiva. Os indivíduos, através da cooperação, partilham as regras da organização assim coletivizada, e participam das decisões concebendo e definindo as políticas a serem adotadas pela empresa, num processo de criação e reapropriação contínua do processo, da organização e dos sistemas de trocas, do trabalho (autogerido) e seu produto.

A questão que se coloca é: como é construído o sistema de representações simbólicas em nível individual e coletivo. Ou seja, como é estruturado um sistema de crenças que suporte e ultrapasse as contradições entre a autonomia e a heteronomia nos sujeitos trabalhadores. Para apreender junto com os trabalhadores estas 
contradições, é preciso propor uma direção metodológica: a história de vida no trabalho e a pesquisa-ação. Temos trabalhado nesta perspectiva, assim como a "observação in loco" e a "conversa ao pé da máquina" (Carvalho, 2000).

Procuramos nos aproximar do objeto de estudo privilegiando a visão do sujeito acerca do fenômeno no qual ele está implicado. O que importa é como o sujeito percebe ou percebeu o fato (coletivo e/ou individual) do qual ele toma parte, assim com sua versão do passado, de forma que esta relação, entre o que é vivido e o que foi vivido, é elaborada neste momento do discurso numa relação de natureza intersubjetiva; do sujeito e/ou do grupo de sujeitos com o pesquisador/ator. Por exemplo, se se vive hoje uma prática de autogestão, como fica a percepção de um passado heterogestivo? Temos ouvido, por exemplo, a expressão: “antes quando tinha patrão era mais fácil”. Longe, como a superfície parece indicar, há presente nesta expressão um desejo de retorno à prática heterogestiva? Ou que se está querendo dizer é da(s) dificuldade(s) que uma prática autogestiva coloca - a qual definitivamente nenhum de nós, como sujeitos sócio-históricos, experimentamos de forma parcial ou plena e portanto inexistente em nossa vivência e vivido prático. Desta forma, possíveis distorções, omitir ou acrescentar informações, fazem parte dessa versão "singular" e é isso é que deve ser ressaltado. É esta visão que norteia o depoimento sobre o vivido e confere significados (sentido) aos fatos narrados, onde o sujeito elabora e encontra saídas para si e para o grupo que o "compreende". É sem dúvida, uma visão subjetiva, mas fornece, ao mesmo tempo, elementos para a compreensão da história do grupo social ou do fenômeno que o sujeito vivenciou ou vivencia, que é, em nosso caso, a experiência laboral autogestiva/ autogerida.

Essa metodologia pode apresentar peculiaridades relacionadas ao sujeito como também servir de suporte para generalizações se for considerado um contexto onde o sujeito cria e partilha os valores construídos no e pelo grupo.

É neste sentido que a posição do sujeito diante da atividade laboral antes e depois da mudança do paradigma produtivo (de heterogerido para autogerido) é importante para ser trazida à tona. Significativo para o sujeito mesmo, que desta forma se "vê" na reflexão que faz sobre 
si próprio e na reflexão que faz em relação ao seu vivido laboral. Criase, assim, uma dinâmica relacional, numa problemática da alteridade como potência simbólica de troca, de reciprocidade.

Esse método de pesquisa é caracterizado não apenas por um trabalho conjunto entre pesquisadores e o grupo alvo, mas também pela investigação associada a uma ação. O que interessa não é apenas o estudo do fenômeno; neste sentido convém ressaltar a importância da formulação por parte de todos os agentes envolvidos na pesquisa, de uma estratégia prática para a solução de questões que podem emergir no decorrer da investigação. Sobretudo no contexto brasileiro em relação aos empreendimentos de autogestão que se confrontam numa luta desigual com o mercado e se constituindo, ainda, experiências minoritárias.

Por ser um método que depende em parte da demanda, ${ }^{5}$ as técnicas e os procedimentos devem ser flexíveis pois as fases da pesquisa são determinadas de acordo com a dinâmica do grupo em questão. Mas isso não impede que um plano de ação seja previamente estruturado, servindo de orientação para os pesquisadores.

Num primeiro momento, é importante salientar a definição de uma fase exploratória, como uma introdução à pesquisa. Essa fase consiste na observação de campo, implicando não só o reconhecimento visual do local de trabalho e a consulta a documentos da empresa. Além desses aspectos técnicos, é importante apreender a dinâmica estabelecida na relação sujeito/trabalho. É o que Carvalho (2000) define como "conversa ao pé da máquina", que tem como objetivo a escuta da estrutura discursiva da atividade em si. É a apreensão do sujeito em processo na própria atividade laboral.

Outra ação que deve ser enfatizada, é a realização de um seminário reunindo a equipe de pesquisadores e membros significativos do grupo de interessados. O objetivo é oferecer aos participantes uma oportunidade para a exposição de propostas e contribuições que permitirão aos pesquisadores a elaboração das diretrizes de ação.

Em relação às técnicas utilizadas para a coleta de dados, estas serão melhor definidas após a realização do seminário. As mais eficazes 
na pesquisa-ação são: observação participante, realização de dinâmicas, grupo focal, oficinas, entrevistas individuais e coletivas e análise documental.

\section{A autogestão em busca da autonomia: do sujeito ao ator social}

O estudo da autogestão, bem como a participação da universidade na estruturação de programas e estratégias que visem ao desenvolvimento de espaços (desde construções estritamente teóricas a espaços físicos de incubação de empresas) nos quais empreendimentos autogeridos encontrem maior facilidade de se desenvolverem, sempre encontra, como qualquer outro projeto de caráter marcadamente social, uma dupla preocupação. Esta pode ser melhor caracterizada como um duplo objeto de estudo que são, de um lado, os fins almejados (baseados em princípios, os quais pré-definem os objetivos que se pretende alcançar) e, de outro lado; os meios utilizados para se alcançar estes objetivos (que também devem estar regidos pelos princípios anteriormente definidos).

A necessidade da coerência entre princípios, meios e fins (ainda que impossível de ser totalmente alcançada) é de fundamental importância ao se tratar de empreendimentos coletivos, principalmente os que pretendem alcançar a autogestão. Assim, a construção de um sistema coerente é fundamental para possibilitar a captação do "sentido" mesmo, sem o qual o empreendimento seguiria por caminhos alheios aos anseios de seus associados na capacidade de intervenção e controle da gestão.

Começando pelos princípios, percebemos, ao caracterizar a autogestão como a autonomia na gestão da empresa por parte dos trabalhadores, que o papel da autonomia para se configurar a autogestão é inconteste. Este termo, entretanto, pode perambular pelos discursos tanto acadêmicos quanto empresariais ou sindicais de maneira imprecisa, necessitando, então, de uma discussão mais aprofundada e rigorosa a partir de seus fundamentos. No entanto, tal discussão ultrapassaria, e muito, as pretensões deste artigo. Aqui para nossos objetivos, ainda que de maneira inicial, vamos situar o contexto no qual consideramos que a autonomia vem a ser um princípio central para se pensar a práxis da autogestão. A noção de autonomia nos 
remete a uma vasta gama de valores e de experiências sociais que tem como centro o princípio da livre determinação do indivíduo, de um grupo ou de um conjunto político maior. De acordo com a filosofia kantiana, que retoma o princípio etimológico do termo, autonomia significa a condição de determinar-se por si mesmo, segundo as próprias leis (...) a autonomia aparece, então, não como a capacidade de agir segundo a lei, mas de definir a própria lei. (Cattani, 1999, p. 27)

No entanto, nossa ponderação parte do pressuposto de que a autonomia se dá como um processo social. Na realidade, as pessoas precisam de leis para viver umas com as outras, a partir do reconhecimento do outro como igualmente portador de direitos. A autonomia se dá então, como projeto de um coletivo. Essa noção se dá a partir da crítica de Max Scheler a Kant, a qual considera que "a pessoa tem autonomia como suporte e realizadora de valores mas essa autonomia se insere em uma comunidade, e especificamente, em uma comunidade de valores, motivo pela qual é de alguma maneira heterônoma," (Mora, 2000, p. 235).

Considerando que, o que nos "interessa é a autonomia efetiva de homens efetivos" (Castoriadis, 1999, p. 67) podemos, dentro dessa mesma linha, ir mais além ao considerar que

essa noção de autonomia não se relaciona com a antiga noção de liberdade, que era de algum modo, imaterial e desligada das constrições físicas. Pelo contrário, essa é uma noção estreitamente ligada à de dependência, e a de dependência é inseparável da noção de auto-organização.(...) A auto-organização significa obviamente autonomia, mas um sistema auto-regulador é um sistema que deve trabalhar para construir e reconstruir sua autonomia e que, portanto, dilapida energia. (...) é necessário que este sistema extraia energia do mundo exterior; isto é, para ser autônomo, é necessário depender do mundo externo (...) esta dependência não é só energética mas também informativa pois o ser vivo extrai informação do mundo a fim de organizar seu comportamento. Mais ainda, toma a organização do mundo exterior (...) Na autonomia há pois uma profunda dependência energética, informática e organizativa do mundo exterior (Morin, 1996, p. 46-47)

A autonomia então, mais que autorganização, se caracterizaria por ser "auto-eco-organização." Além do mais, a autonomia se dá de 
forma efetiva, pois mesmo "o indivíduo mais heterônomo está sempre em condição de fazer exibir, como lembrava Freud, uma parcela de originalidade e autonomia" (Morin, 1996, p. 46-47) no cotidiano do trabalho de uma empresa autogestionária.

Poderíamos considerar que a noção de autonomia, muito mais que uma noção que rompe com o paradigma teocêntrico, deve ser uma noção que rompe também com o paradigma antropocêntrico, se inserindo em algo ainda vago que poderíamos provisoriamente intitular de paradigma "ecocêntrico".

Essa perspectiva é de fundamental importância ao pensarmos na forma de inserção da universidade junto aos empreendimentos econômicos autogestionários. De fato, esta perspectiva abre a possibilidade da consideração de múltiplos agentes que, apesar de interinfluentes, são regidos por diferentes lógicas, possuindo diferentes atribuições e intenções.

Esses diferentes agentes, influentes no processo de gestão, podem alcançar a necessária coerência citada anteriormente na medida em que participam de um projeto mais amplo, situado em uma esfera políticoontológica superior, que abarque os diferentes agentes implicados na busca e na construção da autonomia.

Aparente incoerência, autonomia e participação se harmonizam ao se considerar a primeira como "um processo sem fim e uma conquista", (Enriques,1997, p .108) ou seja, como um projeto de emancipação do homem (que é uma criação autônoma do homem), do qual pessoas, instituições, lugares sociais, teorias, expressões artísticas, projetos políticos, entre outros, participam ou não. Autônomo porque criado, sustentado e desenvolvido pelo homem, do qual participamos porque não se resume a uma pessoa, nem mesmo a uma época ou cultura, mas a um anseio da humanidade, em todos os tempos e lugares. A consideração da autonomia de uma instituição, de uma pessoa, de um projeto político pode (e deve) ser considerada na suas singularidades, mesmo porque é através delas que a autonomia existe de maneira objetiva, mas sem perder a perspectiva de que estas singularidades estão inseridas em um projeto maior. 
O papel da universidade, e de qualquer grupo que pretenda desenvolver tecnologias de gestão ou de intervenção junto a empresas autogestionárias, deve levar em conta a inserção nesse projeto de emancipação da humanidade. Cabe ressaltar que essa emancipação se diferencia das propostas anteriores, como da proposta iluminista de emancipação do homem das forças da natureza, ou da emancipação do trabalho, defendida por certas correntes marxistas, ou mesmo da emancipação dos processos inconscientes, como gostaria algumas correntes modernas da Psicologia americana. A emancipação a que nos referimos refere sobretudo à ilusão de que buscar superar nossos limites é buscar o ilimitado, buscar o poder absoluto. Parafraseando o político português Mario Soares, devemos nos tornar não homens de poderes, mas, homens de liberdades.

Aqui a universidade entra com sua fundamental contribuição que é a de buscar, a partir de um referencial crítico, pela sua condensação de saberes e tecnologias, auxiliar na sistematização, tão importante para a percepção da coerência (e das não coerências) no processo de busca e construção da autonomia. Admitindo a autonomia como auto-ecoorganização, toda organização que pretenda fazer parte do projeto da autonomia deve reconhecer sua parcela de não-saber, "fonte de um certo mal-estar atual, que não se resolve com nada do já conhecido e exige, portanto, o comparecimento dos 'outros' saberes (as ciências) para sair do impasse em que se encontram” (Lousicer, 1997, p. 68). Ser esse outro da organização, eis o papel da universidade.

\section{O jogo das inter-relações: configurando princípios "solidários" do conhecimento}

Dentro do contexto das considerações citadas acima, pensamos ser interessante enfocar alguns dos aspectos de forma mais aprofundada, sem no entanto esgotar a densidade do tema.

Um ponto de destacada importância ao se pensar a autonomia, em seu exercício concreto, é o da autonomia dos diferentes agentes que fazem parte de um empreendimento autogestivo. Consideremos, por exemplo, uma empresa autogestionária de trabalhadores do setor metalúrgico. Vários são os aspectos com lógicas próprias, mas em 
processos de interação. O mercado, a cultura do local onde a empresa está situada, a história de vida de cada trabalhador, a disponibilidade tecnológica e financeira da empresa interferem na forma como a autonomia vai ser "buscada" e no grau de dificuldade para se buscá-la.

Focalizemos, por exemplo, duas diferentes perspectivas de busca da autonomia e como a relação entre elas se estabelece. Essas perspectivas serão, de um lado, a do trabalhador, de outro a da empresa.

Tanto os trabalhadores quanto as empresas possuem suas demandas próprias, que exigem e competem pelos investimentos dos bens adquiridos no exercício do trabalho. Comprar uma máquina nova (que vai possibilitar reduzir o custo do produto final) ou dividir as sobras entre os trabalhadores ao final do exercício fiscal para estes investirem em compras pessoais? Ou investir na capacitação técnica do trabalhador? Questões do cotidiano da gestão de uma empresa autogestionária, que na realidade se referem a uma questão maior, que é a da sistematização entre os diversos agentes atuantes na construção da autogestão. Isso porque o que faz sentido e deve ser buscado para o bem da empresa não é necessariamente o mesmo que deve ser considerado para os trabalhadores.

Um exemplo disso é a dificuldade (pelo menos no Brasil) encontrada por boa parte dos trabalhadores que assumem as empresas nas quais eram anteriormente trabalhadores assalariados, ${ }^{6}$ os quais não estão capacitados tecnicamente para a gestão do empreendimento. Muitas vezes "o gerente-operário tem de aprender fazendo e não podem se permitir muitos erros porque muitos podem ser fatais" (Singer, 1998, p. XXXII). Esta asserção, correta do ponto de vista da empresa, pode não ser tão correta do ponto de vista do trabalhador, pois a partir de certos erros ele poderá, talvez, aprender o que houve de errado anteriormente. $\mathrm{O}$ trabalhador se coloca numa posição de questionamento quanto aos aspectos relativos à administração da empresa, quanto a aspectos relacionados à sua própria forma de se portar com os outros, suas expectativas e sonhos, e se reinserir, agora de maneira renovada, no projeto de busca da autonomia, fazendo parte de outra empresa, trazendo novos questionamentos e com novas propostas, que podem resolver algumas dificuldades não superadas pelo movimento de empresas autogestionárias de maneira geral. 
O mesmo vale para as empresas que denominamos "coopergatos", as quais são cooperativas que, ao invés de se inserirem neste projeto de busca pela autonomia, são caracterizadas por manterem a estrutura de poder de uma empresa heterogestionária (mascarada pela forma da cooperativa, mas apresentando uma dinâmica na qual as estruturas de acesso às decisões ficam inviabilizadas devidos a diversos fatores, tornando-se somente uma forma de precarização do emprego). Essas empresas, por mais que estejam em desacordo com a lei trabalhista, e com o próprio projeto da autogestão, fornecem aos trabalhadores elementos para o questionamento da estrutura vigente que podem leválos à tentativa de superação das incoerências percebidas, principalmente se superado o medo e a acomodação.

O que tentamos demonstrar acima é a necessidade de se analisar uma empresa de autogestão, não a partir da lógica que rege as empresas (ou que regem a produção de riquezas), mas, sim, pela lógica que rege a emancipação do homem na sua busca e construção da autonomia. Mais uma vez, buscar-se-á não o poder (das instituições e da riqueza), mas a liberdade (para a maior expressão do homem como ser humano).

Dentro da perspectiva acima citada propomos algumas considerações para servirem de base para a construção de categorias de análise para as empresas de autogestão, doravante denominados EES (Empreendimentos de Economia Solidária - cf. Projeto de pesquisa UNITRABALHO - Significados e tendências da economia solidária no Brasil)

Procuraremos investigar e analisar os significados que são atribuídos e construídos pelos trabalhadores para nomear, explicar e se situar, dentro de um contexto mais amplo, os diversos fenômenos e situações que são percebidos e vividos pelos mesmos.Para tal dividiremos nossa análise em três dimensões, ou perspectivas, que se constituem em três níveis da organização dos EES que, para fins didáticos apresentaremos em formas separadas, ainda que estes níveis estejam intricados, complementando-se e diretamente implicados uns nos outros, não havendo independência de um em relação ao outro (nem ordem hierárquica). Neste sentido, a mudança em uma das perspectivas, acarreta necessariamente a mudança, em maior ou menor grau, do todo, assim 
como a mudança dos aspectos específicos. Além disso, em cada nível estão implícitos aspectos das outras duas perspectivas. São elas, a saber:

1) Dimensão jurídico-econômica - engloba todo o campo das formas de ordenação legais e econômicas às quais o EES está submetido, sejam elas internas ou externas. Fazem parte deste campo de análise as leis, tanto as criadas e desenvolvidas pelos trabalhadores no âmbito do próprio EES assim como as leis gerais do país. Além disso, considera também as formas de estruturação econômica do EES, seu acesso ao crédito, mercado, parcerias, bem como os diversos bens de produção material e intelectual, e a situação dentro da economia de maneira mais ampla, assim como da própria dinâmica desta economia. A análise dos aspectos jurídico e econômico dá-se mutuamente em função da correlação entre a estrutura normativa da primeira e a função dinâmica da segunda, havendo uma interdependência de ambas na estruturação do EES. Justamente esta interdependência e sua influência na possibilidade de se alcançar a autogestão de maneira viável é o que nos interessa como objetivo de análise.

2) Dimensão político-administrativa - engloba as diversas formas de exercício do poder e do controle, assim como os mecanismos gestionários e suas implicações. Neste nível, nos interessa-nos a relação entre as diversas formas de exercício do poder e as resistências aí encontradas e apresentadas a essas formas de exercício ou de reprodução do poder. Fazem parte deste campo de análise as diversas estruturas de gestão do EES, as formas de dominação e resistências, as formas de acessos às instâncias decisórias, os mecanismos de informação e formação da força de trabalho no sentido da compreensão dos processos administrativos e da dinâmica do mercado. Englobamos aqui, também, a participação no poder local e nacional e as formas e estratégias de acesso a esse poder, assim como as implicações para os participantes do EES dessas diversas formas de exercício e luta pelo poder na organização geral da sociedade e da comunidade. 
3) Dimensão sociopsicológica - engloba todo o grupo de relações e interações intersubjetivas que se estabelecem entre os trabalhadores e entre estes e o EES, seu modo de gestão e execução do trabalho. Esta dimensão engloba também as construções intersubjetivas dos significados e identificações coletivas, bem como a percepção de sua localização dentro de um contexto mais amplo. Fazem parte deste campo de análise a construção do entendimento coletivo sobre o trabalho e a gestão do EES, as identificações e as identidades coletivas dos trabalhadores, os choques que podem existir entre estas identidades/identificações e as formas de expressão intersubjetiva deste choque, bem como os medos e fantasias que povoam o imaginário desses trabalhadores, tendo em vista o sofrimento psíquico que se estabelece nesse processo. Além disso, fazem parte deste campo os espaços informais (e em alguns casos também inconscientes) de resolução de conflitos, de produção de conhecimento e de estabelecimento de metas e princípios orientadores do EES pelos sujeitos trabalhadores.

Estas dimensões, como havíamos dito anteriormente, devem ser compreendidas como interdependentes e implícitas umas nas outras. Portanto, nossa análise deve considera-las a partir dessa complexidade. No entanto, devemos também definir alguns pontos para nos situarmos no âmbito da relação entre autogestão e seu processo de viabilidade. Para isso sugerimos alguns princípios:

1) Princípio da diferenciação - O primeiro ponto dá-se a partir da constatação de que em todos os níveis pode ocorrer uma certa diferenciação entre os princípios e a dinâmica do EES de um lado, e os princípios e a dinâmica do ambiente no qual o EES está inserido, por outro lado. Esta diferenciação não se refere, portanto, à natural diferença entre o nível local de um acontecimento e o nível geral no qual ele se situa, mas remete a diferentes atribuições de legitimidade e afiliação. A partir desta constatação, consideramos necessária a análise do EES na sua inserção conflitiva com o meio que o cerca, seja econômico, legal, político, administrativo, valorativo, cultural, simbólico ou propositivo, assim como os modos de expressão desse conflito nos discursos e práticas dos trabalhadores e do 
EES, bem como o nível de estruturação desse conflito e das estratégias, defesas e categorias de entendimento construídas para se lidar com ele.

2) Princípio da interdependência - Um segundo ponto é o da própria interdependência entre as dimensões de análise. Este ponto, apesar de ser considerado até mesmo na própria estruturação das dimensões de análise, não exclui a necessidade de tentar apreender o EES como um todo, sendo este todo entendido como diferente da simples somatórias das partes constituídas. Para isso é necessário compreender que as três dimensões ou perspectivas analíticas mais do que se auto influenciarem, se auto constituem simultaneamente, estando interdependentes não só no nível dinâmico, mas também no nível ontológico. Neste sentido, há algo de jurídicoeconômico e psicossocial no político, assim como há algo de jurídico político e psicossocial no econômico e assim por diante. Portanto, a questão que se coloca a partir desta evidência é a necessidade de analisar o que seria uma quarta dimensão ou perspectiva de análise, que englobaria todo o EES. Isso significa que a autogestão, para existir, precisa apresentar viabilidade tanto jurídica e economicamente como política e administrativamente, assim como psicossocialmente, ou no que nos assinala Castoriadis (1987, p. 424) "a autogestão só tem sentido quando ela combate as condições instituídas de heteronomia.".

3) Princípio da construção crítica - Por fim, cabe ressaltar as diferenças entre as construções de significado próprias dos trabalhadores e as referentes à equipe de pesquisa. Esta consideração se faz importante na medida em que nos remete a uma percepção crítica de nosso conhecimento, que se transforma a si mesmo em uma categoria a ser analisada no contato de duas diferentes formas de percepção sobre a mesma realidade, assumindo assim uma posição crítica, uma postura de vigilância epistemológica (Carvalho, 2001) que se transforma em espaço de conhecimento de nós mesmos a partir do outro, mas também do outro a partir de nós, procurando estabelecer um espaço de construção de saber no qual o nosso 
saber, na tentativa de entender o saber dos trabalhadores, passe a construir conjuntamente com o saber deles uma percepção mais rica e que abra um maior leque de possibilidades de transformação da realidade no sentido da implementação da autogestão.

Com estas formulações propomos não só categorias de análise e aspectos já percebidos das tendências e significados dos EES, mas aspectos a serem considerados durante qualquer investigação neste contexto e para estudos futuros sobre o tema, aos quais vários outros irão se somar, que esperamos sejam aperfeiçoados a partir do seu uso na atividade de pesquisa e de reflexão sobre a realidade dos EES.

\section{Conclusão: a autonomia e a solidariedade, ingredientes de uma teleologia utópica}

Como podemos perceber, a temática proposta é de complexa apreensão, pois trata de aspectos de vários campos do conhecimento entre os quais, de forma evidente, a Sociologia, a Filosofia, a Ciência Política e a Psicologia. Vamos aqui insistir em que a condição central para que haja a possibilidade da autogestão é a existência da autonomia.

No entanto, a autonomia não se configura como uma dada situação pura e estática, mas como situação processual e, neste sentido, a ser conquistada através da luta dos trabalhadores na dinâmica do modo de produção capitalista no âmbito do conflito inelutável entre capital e trabalho, apontando alternativas outras como as solidariedades urbanas emergentes, tal é o caso do movimento de autogestão em curso.

Na realidade do EES, o exercício da autonomia deve ser visto a partir da forma como se dá a gestão das diversas áreas do empreendimento, compreendendo tanto aspectos objetivos e subjetivos no que tange à administração,à organização do trabalho e às definições relativas aos valores e metas da empresa.

Mas, em que se configura a autogestão nestes aspectos e como identificar até que ponto o trabalhador está agindo de maneira autônoma, 
ou buscando a autonomia? Até que ponto o trabalhador está sendo simplesmente o "operador" de um trabalho definido por outrem e, quais são as contradições inerentes a esse processo de "conquista da autonomia"?

Nesta direção, lembramos o que nos diz Cohen (apud Zool, 2001): a solidariedade implica a capacidade de se identificar com o nãoidêntico. Em outras palavras, a solidariedade implica a aceitação do outro como outro. Com efeito, aqui é o princípio do reconhecimento da diferença estruturante como meio de chegada à alteridade e, dessa forma à construção da solidariedade, mediada pelo “dom”, diríamos nós.

Para se trabalhar estas questões faz-se necessário ir ao encontro do discurso e da práxis mesma dos trabalhadores em processos de autogestão. Nesta direção nos interessa a ótica desses sujeitos, para procurar compreender o que é vivenciado/experimentado como exercício autônomo do trabalho e da gestão na empresa e o que são, neste caso, as condições limitadoras deste exercício, que se configura também como exercício de construir indicadores analíticos para se configurar a vivência da atividade autônoma - do ponto de vista da subjetividade dos trabalhadores - e suas implicações no processo de busca pela autonomia na gestão do EES, sendo o "dom" aqui considerado como mediador simbólico operativo dos laços de solidariedade.

É sabido que um colapso sistêmico do modo de produção capitalista determinou de certa forma a profusão de empreendimentos que buscam uma saída para a crise econômica presente no país. Isso se dá devido a diversos motivos, podendo se relevar entre eles o alto nível de desemprego, a tendência cada vez maior à terceirização da produção, e a desestatização do controle do cooperativismo. Outro aspecto determinante (encabeçado pela ANTEAG), é o movimento de mobilização dos trabalhadores para subsumir a massa falida das empresas como pagamento de direitos trabalhistas devidos.

No entanto, muitas vezes, essas empresas não conseguem implementar a autogestão. Isso se dá por diversos fatores, que vão desde dificuldades intrínsecas à própria organização da empresa autogestionária, até à internalização dos valores intrínsecos à atividade de autogestão, mas no entanto, não se restringem a eles. Por isso, convém 
sempre lembrar que o trabalho, nestes tempos pós-fordistas, repousa (os empreendimentos antes de serem assumidos pelos trabalhadores) sobre uma certa mobilização da autonomia dos sujeitos - mas para objetivos heterônomos, como assinalamos no princípio deste artigo.

Os estudos sobre a autogestão tratam, na sua maioria, sobre aspectos relacionados à organização econômica e administrativa dessas empresas, muitas vezes desconsiderando o aspecto humano, ou considerando-o a partir de pressupostos característicos da análise de organizações heterogestionárias, como a análise dos recursos humanos a serem administrados por um especialista. Assim bem como nos mostra Caillé (2000), quando nos coloca que um dos modos privilegiados de submissão ao trabalho reside justamente em seus mecanismos de troca e, notadamente, na transformação da troca simbólica em troca mercantil, onde se impõem normas de equivalência e racionalidade.

O fator humanoé, no entanto, fundamental para que essas empresas consigam se estruturar enquanto empresas autogestionárias e possibilitar um espaço de mudança social e mudança da organização do trabalho.

Neste momento, faz-se necessário caracterizar o que se entende por um empreendimento autogestionário: ${ }^{7}$ é aquele que se baseia em "um sistema de organização das atividades sociais, desenvolvido mediante a cooperação de várias pessoas(...), onde as decisões relativas à gerência são diretamente tomadas por quantos aí participem, com base na atribuição do poder decisório às coletividades definidas por cada uma das estruturas específicas" (Follis, 1997), são então identificados dois aspectos fundamentais para que haja a atividade de autogestão na empresa, "a primeira é a superação da distinção entre quem toma as decisões e quem as executa, no que respeita ao destino dos papéis em cada atividade coletiva organizada com base na divisão do trabalho. A segunda é a autonomia decisória de cada unidade de atividade, ou seja, a superação da interferência de vontades alheias a coletividades concretas na definição do processo decisório" (Follis, 1997), e por fim devemos considerá-la como "uma entidade organizada de indivíduos coligados entre si por um conjunto de regras reconhecidas e repartidas, que definem os fins, os poderes e os procedimentos dos participantes, com base em determinados modelos de comportamentos oficialmente aprovados" (Cesareo, 1997). 
A partir dessas definições podemos entender como empresa autogestinária aquela na qual os trabalhadores se responsabilizam tanto pela produção, quanto pela gestão da empresa, além da definição dos fins e normas a serem considerados para a organização da empresa, podendo ainda acrescentar que a eles também é conferida a decisão sobre o encaminhamento dos resultados obtidos pela empresa, como a produção de excedente financeiro ou de outros bens e serviços que dela possam advir. A autogestão se realiza, então, como a implementação, no cotidiano do EES, do principio geral da autonomia.

Essa busca pela autonomia na gestão de uma empresa só pode se dar, no entanto, com a autonomia tanto do sujeito trabalhador quanto do grupo, do conjunto dos trabalhadores donos da empresa. Essa autonomia conjunta tanto do grupo quanto do sujeito só será possível através da busca de "uma autonomia voltada para o bem comum e o interesse geral” (Enriquez, 1999, p. 83).

No entanto, podemos observar que, no cotidiano das atividades da empresa, a possibilidade de realizar a gestão de maneira autônoma esbarra em diversas dificuldades. Considerando que, "ao se falar de gestão, está se falando na própria administração do negócio, isto é, na forma de se conceberem ou gerirem todos os recursos envolvidos na produção de um bem ou serviço," e que a gestão se refere ao "processo ativo de orientação e determinação do caminho a ser seguido por uma empresa para a realização de seus objetivos, compreendendo um conjunto de análises, decisões, comunicação, liderança, avaliação, controle e outras atividades próprias da administração" englobando "a determinação dos objetivos e da filosofia da organização, do desenho da estrutura, da organização do trabalho, da natureza das relações hierárquicas, mecanismos de decisão e de controle, entre outros aspectos" (Garray, 1999, p. 101).

Nesta dimensão, podemos constatar a necessidade de um saber a respeito da empresa que seja diferenciado (em relação ao saber demandado do trabalhador em uma empresa tradicional - ou heterogestionária) e da existência de uma dinâmica comunicativa que possibilite o surgimento de uma "inteligência social, ou seja, da capacidade para captar energias, necessidades e potencialidades e 
transformá-las em resultados coletivos" (Autogestão, 2000, p. 7), que dêem conta da resolução das necessidades de gestão da empresa.

Essa inteligência social (ou coletiva), no entanto, esbarra muitas vezes na baixa qualificação profissional, além da não capacitação para exercer atividades administrativas que requerem, muitas vezes, um grau de especialização elevado. ${ }^{8}$

Além disso, quando se troca informações não se trocam somente dados técnicos, mas também experiências subjetivas, o que produz resistências, o que impede que essa inteligência social construa um conhecimento sobre o todo da organização.

Consideradas as dificuldades e limites apresentados, podemos nos colocar então a seguinte questão: como saber o que se constitui o exercício da autonomia real na gestão de uma empresa e em que se caracterizaria a busca da mesma, visto que a autonomia refere-se a uma dinâmica processual?

É preciso, portanto, ir de encontro aos sujeitos reais que vivenciam a busca dessa autonomia em processos de autogestão para que possamos analisar mais profundamente a forma como eles experimentam o exercício autônomo da gestão e do trabalho, assim como a privação deste.

Faz-se necessário, então, pensar a vivência dessa autonomia na gestão da empresa a partir da subjetividade do sujeito, ou seja, "a partir das vivências e experiências adquiridas no mundo do trabalho" (Nardi, 1999, p. 240) e de sua "diversidade de experiências e saberes" (Lousicer, 1997). Essa subjetividade "não é apenas aquela que se orienta em oposição à 'objetividade' (mundo real, concreto empírico) (...) o sujeito se constitui com relação à outro sujeito (relação intersubjetiva), ou seja, não há diferença entre o sujeito psíquico (sujeito da história individual e do desejo inconsciente) e sujeito social (sujeito da história social e de suas transformações)" (Lousicer, 1997). Além disso, a subjetividade possui uma dimensão crucial de ser "um instrumento de auto conhecimento para o sujeito" (Carvalho, 1996).

Para se pensar esta vivência, faz se necessário apreender como emerge o conhecimento pelo próprio sujeito, dessa vivência que se constituiria seu próprio "meta espaço" ou seja, a partir da própria 
compreensão que o sujeito faz de si mesmo, sabendo que a subjetividade é constituída mesmo de responsabilidade pelo outro, retomando aqui, neste momento uma dimensão ética do dom, como dissemos anteriormente, no que ele pode atuar como agente de solidariedades na perspectiva do trabalho como emancipação, no sentido mais nobre e largo do termo.

\section{Notas}

1 Assim como alguns autores têm defendido a concepção de "socioeconomia", defendemos a noção de socioreestruturação produtiva, pois as esferas sociais, assim como as esferas econômicas, são ao mesmo tempo reconfiguradas, sofrendo ambas impactos determinantes para o mundo do trabalho.

2 "Foi longa a corrida atrás de recursos nos corredores de órgãos governamentais, gabinete do governador e Banespa, pelos funcionários da Makerly até, finalmente, ser autorizado o financiamento"( ANTEAG, 2000).

3 Por exemplo, no Rio Grande do Sul, o governo adotou a economia solidária como uma das prioridades; em Belém, a Prefeitura capacita famílias do Programa Bolsa-Escola para a organização de cooperativas; em Minas, em Belo Horizonte, já existe um Ante-Projeto de Lei propondo um Programa Municipal de Incentivo à Recuperação de Empresas sob o Controle Gestionário dos Trabalhadores (Pró-Autogestão)

4 Conforme documento do Fórum Social Mundial, este "será realizado todos os anos, a partir de 2001, simultaneamente ao Fórum Econômico Mundial, que ocorre em Davos, Suíça, sempre no final de janeiro. Esse Fórum Econômico tem cumprido, desde 1971, papel estratégico na formulação do pensamento dos que promovem e defendem as políticas neoliberais em todo o mundo. O espaço criado pelo Fórum Social Mundial estará voltado para formulação de alternativas, para a troca de experiências e para a construção de táticas e estratégias entre ONGs, movimentos sociais, sindicatos, associações e entidades religiosas, em cada país e em nível continental e mundial". Participamos do movimento de preparação desse megaevento, como pesquisador (observação-participante) e sindicalista (participaçãoobservante), contribuindo em vários momentos de debate e divulgação do mesmo o que nos deixou ainda mais convictos da importância de nossos estudos atuais. 
5 Como a análise institucional muito bem demonstrou, há sempre uma encomenda e uma demanda "implícita".

6 Principalmente as empresas ligadas à Associação Nacional de Trabalhadores de Empresas de Autogestão e de Participação Acionária, disponível em: http/ /www.anteag.org.br

7 Os conceitos de autogestão e de empresa autogestionária geralmente são identificados estritamente com as experiências de organização política e de produção adotadas em alguns paises socialistas, principalmente a experiência da Iugoslávia, e em menos grau experiências na Polônia e na Tchecoslováquia. Para o presente utilizaremos empreendimento no sentido de se diferenciar de empresa e colocar em primeiro plano a ação humana de base cooperativa real...

8 Essa realidade vem sendo lentamente, porém de maneira concreta, alterada devido a iniciativas como o sistema de incubadora de cooperativas da UNITRABALHO e os programas de capacitação em MBA da ANTEAG.

Abstract. To this article, the issue treated is to discuss the notions of auto-management and autonomy, such from the theoretical as from the methodological point of view, in the context of the enterprises of the auto-manegement. We therefore search, to propose in this work the necessity of identifying the relations among the following levels of analysis: juridical-economical, political-administrative and psyco-social, in the tension wich is made to be felt between the processes of autonomy and heteronomy. We could think the subject in its relations with "the other" in a new ground of "co-operatio"? In these new configurations of partner-auto-manegement, the social link could not be realizing itself under the format of "donation"?

Resumé. Il s'agit, dans cet article, de remettre en question les notions d'autogestion et d'autonomie, aussi bien du point de vue théorique que méthodologique, dans le contexte des entreprises d'autogestion. Nous cherchons à proposer, dans ce travaille, la nécessité d'identifier les relations entre les niveaux suivant d'analyse: jurídico-économique, politico-administratrif et psyco-social, par la pression qui si fait sentir entre les procédés d'autonomie et de heteronomie. Nous pourrions penser le sujet dans sa relation avec l'autre, sur un nouveau terrain de "collaboration"? Dans ces nouvelles configurations socio-autogestionnaires, le lien social ne pourrait-il se réaliser sous la forme de "don"? 


\section{Referências bibliográficas}

ANTUNES, R. Os sentidos do trabalho. São Paulo : Boitempo, 2000.

ARNSPERGER, C. Mauss et l'ethique du don; les enjeux d'un altruisme methodologique. Revue du MAUSS, Paris, n.15, p. 99, 2000.

BOBBIO, Norberto; MATTEUCCI, Nicola; PASQUINO, Gianfranco. Dicionário de Política. 9. ed. Brasília : Ed. Unb,1997.

CAILLÉ, A. La rareté reconsideré. Revue du MAUSS, Paris, n. 18, p. 119, $2^{\mathrm{e}}$ sem. 2001

CARVALHO, Ricardo Augusto Alves de. Les nouvelles technologies de 4gestionet la mobilization de la subjetivité dans une industrie au Brésil. Paris : Presses Universitaires du Septentrion, 1996. Tese (Doutorado).

. Gestão do trabalho/gestão do sujeito: novos ingredientes da competência organizacional. Belo Horizonte : NESTH/UFMG, 1998.

. Em busca do método: contribuições para um novo paradigma científico. ANPEPP, 2000a.

Significados e tendências da economia solidária no Brasil: relatório final, Minas Gerais. 2000b.

. Configurações teórico-metodológicas sobre as novas configurações autogestivas no mundo do trabalho neste início de milênio. Belo Horizonte : NESTH/UFMG, 2001

CASTORIADIS, Cornelius. As encruzilhadas do labirinto: os domínios do homem. São Paulo : Paz e Terra, 1987.

. As encruzilhadas do labirinto $V$ : feito e a serfeito. Rio de Janeiro: DP\&A, 1999.

CATTANI, Antônio David (Org.). Trabalho e tecnologia: dicionário crítico. 2. ed. Petrópolis (RJ) : Vozes, 1999.

ENRIQUEZ, Eugène. A organização em análise. Petrópolis (RJ) : Vozes, 1997.

. Perda de trabalho, perda da identidade. In: NABUCO, Maria Regina; CARVALHO NETO, Antônio (Orgs.). Relações de trabalho contemporâneas. Belo Horizonte : IRT/PUC-MG, 1999.

GARRAY, Ângela. Gestão. In: CATTANI, Antônio David (Org.). Trabalho e tecnologia: dicionário crítico. 2. ed. Petrópolis (RJ) : Vozes, 1999.

LOUSICER, Eduardo. A pró-cura da subjetividade: a organização pede análise. In: DANIEL, Eduardo; VASCONCELOS, João. Sujetividade e recursos humanos. 2. ed. Petrópolis (RJ) : Vozes, 1997. 
MORA, José Ferrater. Dicionário de Filosofia. São Paulo : Loyola, 2000.

MORIN, Edgar. A noção de sujeito. In: Novos paradigmas: cultura e subjetividade. Porto Alegre : Artes Médicas, 1996.

NARDI, Henrique Caetano; TITTONE, Jaqueline; BERNARDES, Jefferson Sousa. Subjetividade e trabalho. In: CATTANI, Antônio David (Org.). Trabalho e tecnologia: dicionário crítico. 2. ed. Petrópolis (RJ) : Vozes, 1999.

SINGER, Paul. Prefácio. In: Empresa social - administração autogestionária e globalização: uma possibilidade de trabalho permanente. São Paulo : ANTEAG, 1998.

SANTOS, Boaventura de Souza. A crítica da razão indolente: contra o desperdício da experiência. 2. ed. São Paulo : Cortez, 2000.

TRANSFORMAR as possibilidades das empresas de autogestão. Jornal Autogestão, ANTEAG, n. 2, jun./jul. 2000. 